This item was submitted to Loughborough's Research Repository by the author.

Items in Figshare are protected by copyright, with all rights reserved, unless otherwise indicated.

\title{
The software-simulated airworld: anticipatory code and affective
} aeromobilities

PLEASE CITE THE PUBLISHED VERSION

PUBLISHER

(C) Pion

VERSION

AM (Accepted Manuscript)

LICENCE

CC BY-NC-ND 4.0

\section{REPOSITORY RECORD}

Budd, Lucy C.S., and Peter Adey. 2019. "The Software-simulated Airworld: Anticipatory Code and Affective Aeromobilities". figshare. https://hdl.handle.net/2134/5832. 
This item was submitted to Loughborough's Institutional Repository (https://dspace.lboro.ac.uk/) by the author and is made available under the following Creative Commons Licence conditions.

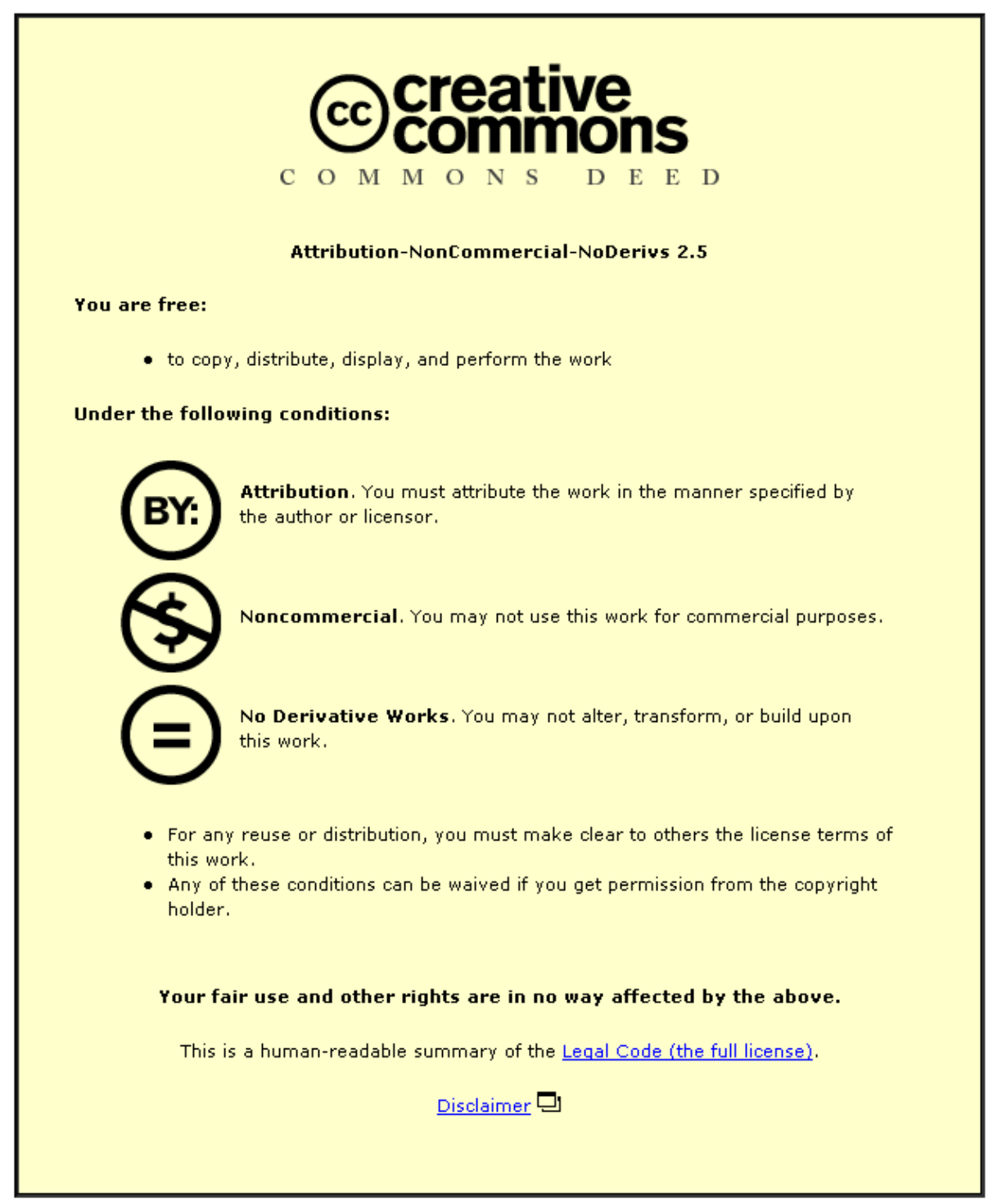

For the full text of this licence, please go to: http://creativecommons.org/licenses/by-nc-nd/2.5/ 
Please cite from the final published version of this paper in Environment and Planning A (2009) 41: 1366-1385.

The Software-Simulated Airworld: anticipatory code and affective aeromobilities Lucy Budd ${ }^{(1)}$ and Peter Adey ${ }^{(2)}$

This paper is concerned with the way airspaces are organised, managed and understood by virtual representations - software simulations that are tested and used both preemptively and in real-time. We suggest that while airspaces are often understood as simulations themselves, models and blueprints for real-world futures (Fuller and Harley 2004), they are among the most mediated of all contemporary social environments, produced not only through code, but based on scenarios that predict and plan for future events - real virtualities that might come true (Dodge and Kitchin 2004). Drawing on historical and contemporary examples of aeronautical software-simulation employed by civilian and military aviation we explore how code has become increasingly sophisticated and ubiquitous in response to the challenges set by the mobilities the simulations model and the affective susceptibility of the corporeal body that uses them. The paper explores how software simulations work to structure and mediate behaviour by producing specific emotional and affective experiences in order to prepare the body for future encounters.

Keywords: aeromobility, software, simulation, virtual space, affect 
(1)

Transport Studies Group

Department of Civil and Building Engineering

Loughborough University

Loughborough

Leicestershire

LE11 3TU

E-mail: L.C.S.Budd@lboro.ac.uk

(2)

Earth Sciences and Geography, and the Institute for Law, Politics and Justice

Keele University,

Keele,

Staffordshire,

ST5 5BG

Telephone: 01782583615

Fax: 01782715261

Email: p.adey@esci.keele.ac.uk 
"[M] odelling and simulation sit uncomfortably in science both socially and epistemically, because of the boundaries they cross." (Sismondo 1999: 247)

\section{Introduction:}

On $2^{\text {nd }}$ November 2006 the United States Air Force launched Cyberspace Command. Complementing their existing Air Combat and Space Command, the new Command facility sought to establish and preserve not only "freedom of access and commerce in air [and] space", but also cyberspace. The increasing use of such networked battle simulations by military forces means that the ability to 'fly' and 'fight' is increasingly being taught in a virtual realm, and code has become a medium through which aerially mobile objects and forces are structured, trained, and coordinated. For the US and other armed forces, computer code, and the infrastructure that carries it, has become a new territorial space whose exploitation enables them to achieve 'full spectrum' dominance (Graham 2004; Weizmann 2002). ${ }^{1}$ Cyberspace, not real space, has become the new territorial 'high ground'. ${ }^{2}$ The importance of computer code to commercial aviation is similarly evident. From the check-in desk to the flightdeck, aeromobile objects and bodies are screened, sorted and monitored by a labyrinth of networked computer systems. For the most part, these systems are taken for granted, and our dependence on them only revealed when a computer breakdown at air traffic control grounds flights or a malfunctioning baggage system misroutes luggage.

Thrift and French (2002) were among the first to articulate the importance of recognising how computer software automatically 'produces space', and other scholars have

\footnotetext{
${ }^{1}$ See Weizmann on the Israeli surveillance of Palestinian airspace

2 http://csat.au.af.mil/2025/volume4/vol4ch02.pdf
} 
convincingly demonstrated that our everyday lives are shaped by interactions with a myriad of different software applications, encompassing everything from apparently innocuous alarm clocks to mobile telephones and the internet (Dodge and Kitchin 2005). Ueno and Kawotoko (2003: 1529) have similarly proposed that space is not given, but actively produced and augmented by the application of technologies that 'make space visible'. In their seminal paper of 2004, Dodge and Kitchin argued that nowhere is this process more evident than in the mediated and controlled sites of air travel. In their view, the unique spatialities of air travel render them emblematic 'code/spaces' of the modern world; spaces that are not only created by code, but utterly reliant upon code to function.

Taking the 'real virtualities' of Dodge and Kitchin's (2004) airspaces as our starting point, together with what Thrift and French (2002) have described as the way software 'expresses the co-presence of different times', we seek to explore the capacity for coded software to act as a form of anticipatory technology. Focusing on the use of different software simulations by the aviation industry, we investigate how these programmes do more than simply predict imminent events or premediate (in Grusin's (2004) terms) possible futures.

As Barnes (2008) and others have shown, geographers have long relied on the use of models and simulations in their research, yet surprisingly little theoretical work has been conducted into the implications of their use within the discipline. Where it has occurred, it has often revolved around the study of computer modelling and simulations as methodological tools for geographical analysis. However, while Dodge and Kitchin (2004, 2005) have gone some way towards examining the kinds of software systems and communication devices which mediate and maintain air-travel operations, the 
relationship between software simulation (as opposed to software code alone) and the mediation of different forms of aeromobility has yet to be adequately charted.

In this paper, we explore how selected aeronautical software systems virtualise potential aerial mobilities in an effort to prepare-for, prevent, or pre-empt some future event, and illustrate the complex geo-political, social and cultural contexts in which they are conceived and employed. Our aim is to move beyond descriptive narration of the pervasiveness of software simulations in discourses of military and civil aviation by suggesting that the simulations themselves deserve increased attention, not only because of their inevitable and sometimes serious 'technogeopolitcial' implications (to borrow Butler's (2001) phrase) or their propensity for violence and inequality, but as a consequence of the production of what Thrift (2004b) might call 'spaces of anticipation', embodied in fore-thought and action, which often perpetuate and mediate such concerns.

Through in-depth archival research and observational analysis, we explore the relationship between simulations and the bodies that use them, investigating the kinds of pre-cognitive, affective and habitual structures of thought and practice which are not necessarily transferred from human to machine (see De Landa 1997), but are emerging through their relationship. ${ }^{3}$ We discover how the digital dataspaces generated by computer simulations affect embodied experiences and perceptions of the real world in order to form 'inculcated corporeal automatisms which result in practical anticipations of how situations can be performed' (Thrift 2004b: 175). In the following section we

\footnotetext{
${ }^{3}$ Our findings are drawn from original research conducted by both authors between 2002 and 2006. Sources included the full depository of the BEA Operational Research department held at the Modern Records Centre, Warwick University; ethnographic observation of the use of commercial flight simulators, and experience of using an x-ray simulation trainer. Thanks and acknowledgement is given to the ESRC for supporting part of this research (PTA-026-27-0943).
} 
contextualise these debates within contemporary studies of aeromobility in the social sciences before re-theorizing simulation software through key literature on affect and human-computer interactions. These conceptualisations are then developed in subsequent empirical sections of the paper, which variously explore both the historical and the contemporary deployment of different forms of aeronautical software simulation. Their implications are discussed in the concluding sections of the paper.

\section{Studying aeromobility:}

For many years, the study of air travel was regarded as something of a niche interest and, despite the inherently geographical nature of flight, geographers initially had little to say about the emerging discipline of aeronautics. During the 1920s and 1930s, a limited number of studies addressed practical issues concerning the suitability of landing grounds and weather phenomena (Blake 1923; Taylor 1919), while others documented the success of pioneering long-distance flights and discussed the strategic geopolitical importance of aviation to the maintenance and administration of empire (Byrd 1925; Light 1935; Sykes 1920; Wilkins 1928). Following the Second World War, geographers were arguably well placed to comment on the development of post-war aviation, but it was not until the quantitative revolution in the late 1950s that sustained studies detailing the network attributes of airline operations began to appear (see Taaffe 1956; 1959; 1962). From then on, geographic studies of air transportation acquired something of a reputation as a specialist subject and rarely appeared in mainstream geography journals (Vowles 2006). It was not until the turn of the millennium that any change occurred. The ready-availability of airline route information on the Internet enabled geographers to describe and visualise evolving airline networks at a variety of scales (Bowen 2002; Burghouwt and Huys 2003; Derudder, Devriendt et al. 2007; Derudder and Witlox 2005; Smith and Timberlake 1998; Smith and Timberlake 1995; Zook and Brunn 2006), while the recent surge in 
interdisciplinary mobilities research has led to new interest in aviation's socio-political and environmental dimensions. As Cresswell (2006) and others have recently shown, flying undoubtedly facilitates long-distance relationships, permits meetings, travel and tourism, fosters economic development and regeneration for some people in some places, yet it also often generates community opposition to aircraft noise and protest against airport expansion and is usually only accessible to the more affluent members of society. Adey, Budd and Hubbard (2007) subsequently identified a paucity of geographic research into the social, cultural and politically inflected dimensions of global air travel and noted that the mundane technical, operational, and logistical infrastructures supporting global aeromobility have been inadequately charted.

The rapid rise of a putative 'mobilities' paradigm (Cresswell 2006; Hannam, Sheller et al. 2006; Urry and Sheller 2006) within the social sciences has begun to alert geographers to the potential overlaps between transport geographies and social-cultural research and demonstrated that there is much more they can, and should, contribute. John Urry has consistently argued that air travel is a central component of modern society (see Urry 2007) and there is evidence to suggest a growing awareness of the importance of air travel to the contemporary world order (see Cwerner et al, forthcoming). Paralleling this increased academic interest, the main site of commercial air travel, the airport, has enjoyed a recent surge in interest by scholars, writers, artists, novelists, journalists and cultural historians. Whether detailing its architectural history (Pearman 2004), lamenting its inefficiencies and idiosyncrasies (Hickman 2007), or discussing the diverse spaces of connection and disconnection, emotion and disaffection witnessed therein (Gottdiener 2000; Iyer 2000), the airport is now frequently described as one of the paradigmatic spaces of the late $20^{\text {th }}$ and early $21^{\text {st }}$ centuries (Fuller and Harley 2004; Gordon 2004). 
More than exemplars of modern life, commentaries posit the aeroplane as an indicator of what is to come. Harbinger of overbearing (in)security, death and destruction on the one hand, the aeroplane seduces and shimmers in technological innovation in the other. These themes are reflected and complicated in recent research directions.

One body of research has started to reflect on the implications of contemporary forms of airport security and surveillance to suggest they are leading to new and increased forms of social coercion and control (Lyon 2003; Salter 2004; 2007), while another has begun to explore aviation's destructive potential and military applications (see also Adey 2008). Though aircraft were first deployed in a military campaign in what is now Libya in 1911, it is only within recent years that authors, including Stephen Graham (2004), Eyal Weizmann (2002), Caren Kaplan (2006) and Alison Williams (2007), have begun to examine the geopolitical significance of the aeroplane to the conduct and outcome of modern warfare and state aggression.

Stephen Graham's (2004) focus on the targeting of infrastructure by aerial warfare resonates with our own interest in the 'sunk' and invisible mediating infrastructures of software and code within the global aviation system. While the vast steel and glass monoliths of the airport system have been targeted by the contemporary ethnographer and scholar of international politics, much of the mundane processes that work to maintain the air transport system, from the screening of baggage to the production of flightplans, remain resolutely hidden and unexplored (see Fuller and Harley (2004), for an exception). This lacuna is unfortunate, as coded software systems undoubtedly mediate the production of airspaces to a significant degree. Unlike Dodge and Kitchin (2004), it is not the presence of the code itself that interests us, but how computer software, in the 
form of models and/or simulations, is used as a means to anticipate (and often mitigate), future events.

\subsection{Theorizing software simulations}

Theoretical investigations into the use of software simulation bridge the physical, natural and social sciences. Sitting on a spectrum of analogic, role-playing and physical simulations that seek to anticipate and/or simplify reality (Sismondo, Gissis et al. 2000), simulations function in a manner akin to what Rheinberger calls 'epistemic objects' (1997) and may range from rigid and unquestioned 'black-boxed' tools to more ephemeral theoretical constructions.

Within Geography, Chorley and Haggett (1967) famously employed physical and conceptual models as a means to escape from the constraints of an idiographic regional geography. Used as tools of analysis, quantitative geographers employed simple models to analyse patterns and growth, as they enabled the 'problem' (reality) to be 'translated into more familiar or convenient terms such that a useful model involves a more simplified, accessible, observable, controllable, rapidly developing, or easily formulated phenomenon from which conclusions can be deduced, which, in turn, can be reapplied to the original system or real world' (1967:128). Models were thus developed to get a handle on a complex reality, to simplify the world into a legible order from which predictions about its form and function could be made (Harvey 1969). More physically demanding models, moulded and built by human hands (Ploszajska 1996), and roleplaying games (Walford 1995; 1981) had specific pedagogical benefits as they enabled students to engage both socially and haptically with the object of study. 
As Trevor Barnes (2001) has argued, the turn towards more scientific modelling was partly an act of pragmatism that gave these sorts of geographies a sense of scientific worth and authority.

'By metaphorically re-describing geographical things in terms of physical models, they found they could use statistical models, make predictions, publish in scientific journals, speak authoritatively about scientific explanation and more besides' (Barnes 2001: 158).

Despite Barnes' claims, very little work before his announcements had sought to concentrate on the models and simulations themselves. Even Doreen Massey pertinently remarked in her forward to New Models in Geography (1989: xi), "I am sure that the meaning, if not the use, of the term 'model' would make a lively topic of debate!"

More recent investigation within human geography, particularly within the subfield of geographical information systems (GIS), has begun to question the use and implications of the 'black box' of the simulation model. As a form of anticipatory technology, simulation models enable predictions to be made about uncertain futures and allow users to run 'what if' scenarios of, for example, alterations in atmospheric chemistry and the impact on the global climate (Shackley and Wynne 1996); the complexity of human mobility in crowds; or the multimodal event of an urban evacuation (Barnes and Farish 2006). As models and simulations move into the public domain their inherent uncertainties and qualifications may be forgotten and the public seduced into accepting their 'crystal ball' like assumptions (Kerr 1994; Shackley and Darier 1998; Shackley, Young et al. 1998). As Barnes (2008) shows in his most recent examination of geography's quantitative revolution (in other contexts see Demerrit 2001; Pickles 1995; Schuurman 2004; Guhathakurta 2002; O'Sullivan and Haklay 2000), social contexts provide powerful frames for the use and deployment of models. Setting the development 
of modelling simulations in the context of Cold War planning, Barnes (2008) illustrates how models were rendered as anticipatory solutions to the demand for the scientific rationalisation and subsequent legitimisation of evacuation planning and transport infrastructures.

Alongside their concern for both the utility and fallibility of models and simulations, geographers have become increasingly interested in a medium that is perhaps just as invisible and ubiquitous - code and software. Evolving from their first studies into the Internet and ICTs, Dodge and Kitchin (and later Thrift, French, and Graham) have provided analysis into the nuanced role that software and code play in mediating and augmenting everyday geographies and inequalities. Whilst the relationship between software and the simulations they enable is often less than clear, the practice of using models and simulations is often constrained by the computing tools and languages in which they were written, limiting their accuracy and potential application.

For those who recognise software and electronic space as being a particularly curbed and regulated space (Lessig 1999), greater flexibility may be witnessed in cultures of simulation software. Sherry Turkle (1995) argues there has been a shift from modernist top-down programming towards more bricoleur forms of simulation. Participatory GIS and novel methods of emplacement in planning, design and architectural previsualisation (Buscher 2006) are becoming increasingly common owing to the 'soft mastery' software simulations allow. As Turkle $(1995,52)$ notes, it is now relatively easy to run "what if scenarios and tinker with the outcome' but she also appreciates that simulations and software often conceal underlying models and assumptions and may result in an 'abdication of authority". The critical address of Geographical Information Systems has shown the 'downstream' (Demeritt 2001) effects of software simulations (Curry 1998) 
for privacy rights, discrimination and direct violence. 'New material geographies' (Graham 1998: 486) are the outcomes of pervasive forms of surveillant simulation. As Barnes (2008) has discussed, models (and, as we will see, simulations), have the power 'not only to represent the world but to intervene' in it and engineer its alteration (Mackenzie 2006).

Far from being complete, research in this area has remained considerably underdeveloped by geographers who are concerned with more nuanced theorisations of embodiment and performance. Arguably, the legacy of science and technology studies (STS) (see Demerrit 2001; Sismondo 2000), has meant that the predominant approach is one that focuses on the unveiling of power structures, or the solicitation of inaccuracies in the translation of scientific knowledge, or other forms of discursive interpretation. A common criticism levelled at investigations of the Internet is that the body has somehow been 'left behind', with the resulting discussions devoid of any bodily emotion or sensation. Even Barnes' recent exploration of simulations within quantitative geography lacks a sense of the sorts of ways the modelling simulations were seen, felt, touched, and practiced in action. It is at this interface that we are concerned with more embodied, emotional and 'more-than representational' questions (as recently detailed by Lorimer 2005; 2008). Specifically, we are interested in the considerable promise of the concept of affect.

Within geography, the notion of affect has been adopted as an (albeit problematic) attempt to make sense of bodily experiences that occur before, during, after, or independently from, different kinds of cognition. Drawing on psychoanalytical and biological writings, together with those of performance theorists and philosophers, a set of debates has emerged that has targeted a domain of experience that could be 
summarised as 'feelings' (Anderson 2004; Dewsbury et al., 2002). Unlike an emotion that is consciously recognisable, affect refers to a visceral bodily feeling. Such feelings are understood as entirely embodied, almost inseparable from other bodily sensations and other bodies. Like the models described earlier, affects and emotions sit on a continuum of feeling states that range from the most primordial human drives and instincts towards those that can be readily described and identified, such as fear, excitement, or hate (Buchanan 1997).

Although a lot of work within geography and the wider social sciences have explored a kaleidoscope of issues surrounding the concept of affect, including the practice of driving (Sheller 2005), being a passenger (Bissell 2008), ballooning (McCormack 2008 forthcoming), security (Adey 2008), music (Anderson 2002), dance (Dewsbury 2002; McCormack 2002) and film (Bruno 2002), all of which are diverse empirical and conceptual domains pregnant with the underlying "potential to widen the scope and multiply the terms of reference of the political" (Carter and McCormack 2007) - little work has gone into examining the relation between affect and technology (see though Anderson 2007; and Clough 2000), or more specifically, affect and software. However, this is not to say that all research has been blind to the relationship, and it is important to recognise that researchers within the fields of Cognitive Science and Human Computer Interaction (HCI) have been addressing the concept of affect as a fundamental component of the relationships and interactions between humans, computers and technology for over ten years.

Tuning into such relations between affect and software has revolved around the call or subfield of affective computing research led by Lisa Picard (2000) who worked on the assumption that people are and will come to "express their emotions through (and with) 
computers" (McNeese 2003: 34). Taking on the affective dimension in HCI and other concurrent movements in cognitive systems engineering (CSE) and computer-supported cooperative work $(\mathrm{CSCW})$ has meant a fuller understanding and modelling of the users of such systems. Explorations are currently underway into the feasibility of using particular theories of human affective and emotional behaviour in computer based software models. These may be put to use in software interfaces that are used to recognize user affect or that may adapt to the user's affective state. Other uses may imply generating 'affective' behaviour or generating affective states (Hudlicka 2003, 3). Examples range from building artificial intelligence software that mimics human feelings and emotions, to software that can train someone to identify and capture 'malicious intent' in drivers or 'hostile intent' in passengers (Adey 2009), to systems that attempt to enable learning without producing the blocking emotions of 'frustration'.

Clearly geographers and other social scientists must be aware of these important developments in other fields, but, for our purposes, a more salient issue is posed by Michael McNeese who points to the difficult question of what happens when these "models, simulations, and expressions of how we act and behave become more heavily coupled to the real world and our internal worlds" (McNeese 2003, 37). We suggest that it is the impact and translation of affective code - which supports the anticipatory technologies of simulation models into the everyday and extraordinary material geographies of flight - that warrants further investigation.

\section{Contextualising the Software Simulated Airworld: rationalities, contingencies} and code:

Before we examine the effects of aeromobile software simulations in great detail, it is important that we consider the context in which such simulations are (and have been) 
used. While we make no effort to provide an exhaustive overview of the chronological development and utility of aeronautical software simulations, we do wish to emphasize their ubiquity within this sphere and note the tendency for simulations to bring human emotion and uncertainty, under calculation.

\subsection{WW2 to the Cold War}

The use of simulation within the air transport industry dates back to pioneering work in the field of Operations Research (OR) in the middle of the twentieth century. OR encompasses a mass of calculative and predictive technologies and procedures and includes "linear programming, queuing theory, simulation techniques, cost-benefit analysis, time series and cross-section statistical estimation, operational gaming patterned upon war games, time and motion study and network analysis" (Mirowski 2001: 180). As a kind of 'combat science' (Rau 2005) Operations Research was developed by the Tizard Air Committee during the Second World War to test and predict strategies of air-defense against aerial attack. OR allowed the likely outcomes of different tactics to be explored in order to produce effective and efficient defensive actions in the event of an actual attack. In response to technological, strategic and tactical change, OR attacked uncertainty and indecision to stop war being conducted by "gusts of mood" and relied on prediction and the subsequent validation of those predictions.

In a commercial context, the Operational Research Branch of British European Airways (BEA) in the 1950s developed "formalised and integrative knowledges of sequence" (Mirowski 2001) that counted and calculated in order to develop an optimal sequence of events that could then be imposed upon reality and translated into practice, thereby refining future plans and restructuring the everyday processes and procedures of the airline to make it more streamlined and efficient. As Mirowski (2001) notes, a 
predominant form of OR was an extension of Taylor's scientific-management of behaviour. Just as Taylor worked to capture, imagine and eventually structure behaviour and bodily movement (see Cresswell 2006; Solnit 2003), the deployment of OR has often been involved in the Foucauldian "discipline of human beings" (Mirowski 2001: 178). BEA's use of OR ranged from changing the layout of check-in desks to facilitate more efficient passenger processing in airport departure halls, to the handling of telephone calls by the flight reservation department. While not yet automated by computer code, OR sought to anticipate future events (such as new procedures or practices), which could then be modeled, rationalized and rendered more efficient, before being imposed upon practice.

Within the military sector, the introduction of OR was able, as Crowther and Whiddington have it, to introduce a kind of distanced, objective and scientific rationality to the conduct of war, preventing war "being run by gusts of emotion and hunches" (cited in Hables-Gray 1997: 140). Indeed, such rationality was perpetuated through what Hables-Gray describes as a turn to a 'postmodern war'. In his view, in a 'postmodern war', the 'concern for planning the future has, in many ways, become more important than fighting wars in the present' and notes that 'even mid-intensity and low-intensity conflicts are planned, and gamed, and simulated' (Hables-Gray 1997: 212).

Having said that, other modes of anticipation were being developed that relied on precisely the sorts of capacities OR attempted to move beyond. Cold War military doctrine was premised upon an ideology of futurism, known as preparedness. Emerging from the early Cold War war-gaming exercises developed by the RAND Corporation, which was then part of the US Air Force (see Anderson forthcoming; Ghamari-Tabrizi 2005), potential battle scenarios were played-out in computer mediated environments 
(Edwards 1996). For Ralph Schroeder (1996), such virtual environments helped satisfy a strategic military need for surveillance and control, while their perceived value enabled them to acquire a "spiritual currency" within militaristic discourse (De Landa 1997). As Anderson (forthcoming) shows, intuition and imagination, as well as affective reactions such as 'shock' and 'surprise', now became valued as felt experiences to be simulated. Advocates, such as Sherry, argued simulations "must become a state of mind so firmly embedded in our souls as to become an invisible philosophy" (Sherry cited in HablesGray, 1997: 133).

\subsection{Digital aviation today}

Within contemporary commercial and military aviation spheres, the legacy of early OR simulation manifests itself through the coded software simulations used in aircraft design, component engineering, equipment testing, and airframe manufacture in order to devise, test and validate a project or design before it is constructed and put into service. The Boeing 777 was the first commercial aircraft in the world to be designed entirely on computers. Through the use of the specially designed CATIA (Computer-aided three dimensional interactive) system, all aspects of the airframe were pre-assembled in threedimensional virtual reality. This digital mock up enabled the designers to see all the airframe's components as three-dimensional solids. This enabled them to identify and resolve any interference or misalignment problems prior to construction and dispensed with the need for traditional paper blueprints and expensive engineering mock-ups (Norris and Wagner 1996). While the shell of the aircraft was being simulated in threedimensions, individual components, including flightdeck displays and cabin atmospheric controls, were tested in the dedicated laboratory where test pilots and engineers 'flew' hundreds of sorties and ran multiple simulations 24 hours a day to ensure the compatibility, reliability, and durability of different aircraft systems. In this way, 
aeronautical software-simulations were used not only to design but also evaluate critical B777's systems, involving technologies that are, themselves, designed to simulate, predict and/or pre-empt future events in commercial service.

The planning and day-to-day management of airspace itself (understood in this context as the space in which aircraft fly) similarly relies on complex software simulations (see Budd, in press) while PAXSim, Total Airspace Modelling Simulation, and others, seek to simulate the complexity of ground operations at individual airports and manage areas of congestion. Thus, from predicting passenger flows in the terminal building to managing the efficiency of the airfield and its surrounding airspace, software simulations are employed to test both the capacity, limitations and efficiency of existing structures and used to test and validate new plans. While some of these simulations may remain rather abstracted or simplified versions of reality, ill-suited or incapable of capturing the diversity and influence of stress and emotion on human behaviour, other simulations attempt to model both the physical attributes of the airport environment (or the aerodynamic properties of individual aircraft) and influence the physiology of those that use or command them (c.f. Gratch and Marsella 2003). Crucially, the embodied performance of the human operator, which was delivered in response to a particular simulation, was recognised as being as, if not more, important than the sophistication of the computer technology (McKenzie 2001). .

In an effort to address the expense and danger associated with staging large-scale multinational live-flying exercises, military agencies began to employ computer simulations during the Cold War to provide realistic tactical battle and flight training platforms for soldiers and aircrew. As popularly detailed in works such as Malcolm Gladwell's (2005) Blink, the incredible processing power that was required to compute 
and simulate mobile objects initially resulted in large, cumbersome, and rigid forms of prediction which were slow and expensive to operate (Wilkes 2001). Today, thanks to continued developments in computer processing, modern Airborne Mission Simulators (AMS), Distributed Interactive Simulations (DIS), and Computer Generated Forces (CGFs) can not only create highly responsive and sophisticated networked virtual battlespaces, but they are cheaper and safer to operate than live exercises and enable international interactive participation. In late 2004, selected NATO members participated in the 'First Warfighter Alliance in a Virtual Environment' (First WAVE), a virtual reenactment of the Bosnian conflict of the 1990s. Here, in a virtual networked war zone, Canadian CF-18 Hornets fought alongside Dutch F-16s, German and Italian Eurofighter Typhoons, British E-3 Sentrys and French Mirage 2000s in their battle for aerial supremacy against mobile Serbian MiG-29s above Bosnia. Significantly though, on this occasion, the bombs and missiles were virtual and the pilots were flying simulators located as far afield as Canada and Italy. Crucially, in addition to accurately modelling the performance of different aircraft and weapon systems, the simulation also aspired to create an 'adrenaline rush' and engender feelings of excitement and fear among its participants in recognition that emotion plays an important role in shaping the outcome of military action (see Gratch and Marsella 2003).

\section{Aeromobile anticipations:}

If we return to the association between software simulation and the objective rationalism of scientific discourse, it appears that simulations, including OR, were traditionally deployed as a means to anticipate and attend to particular futures, enabling complex plans and designs to be tested and validated before they were built or enacted. At the time, some considered software simulation to provide a veneer of scientific legitimacy, allowing emotion, moods and human intuition to be jettisoned in favour of rationalism, 
calculation and mathematical probability. However, we contend that modern aeronautical software simulations are interesting precisely because they do not jettison human emotion, but bring it under calculation.

As we saw in the later instances of virtual battle spaces, certain simulations are designed not to predict a future event, but to prepare, train, and condition the human body to deal with unpleasant kinesthetic sensations, including rapid acceleration, disorientation, intense G-force and airsickness, as well as physical exertion, fear, and prolonged periods of intense concentration. Following Anderson's (forthcoming) treatment of preparedness as a mode of securing potential futures (see also Collier, Lakoff et al. 2004; Lakoff 2007; Massumi 2005b), we contend that certain types of aeronautical software simulation actively target such affective behaviour (see also Anderson 2006; Massumi 2002; McCormack 2003). Here, gut feelings, intuitions, instincts, motivation, snap decisions, moods, emotions and bodily dispositions are intentionally fostered, constructed and entrained by software simulation systems, creating a kind of bodily-reflexivity or automation that enables the user to address certain events almost subconsciously. In training particular stances towards uncertain and unpredictable mobilities, such as readiness, alertness and attention, we can see a trend towards virtual environments that attempt to encourage what could be thought of as a sense of 'preparedness' or “anticipatory readiness" (in Nigel Thrift's terms (2006: 286)) for future events that one hopes will never be realised.

\subsection{Digital bodies and immersive simulations}

As well as enabling people to use existing airspace in new ways, simulations also open up the possibility of creating entirely new (air)spaces which, we suggest, push forward the ways in which a simulation addresses the user's body-subject. Crucially, we argue this is 
not done as a way to rationalise decision-making and dull embodied experiences of mood and feeling, but rather to intensify and heighten such experiences. Describing his first 'flight' in a new virtual reality hang-gliding simulator, Jon McKenzie (1994) remarked on the importance of physical action and bodily sensations in making the experience 'real'. Unlike older machines, the new simulator required its users to wear both a display hood and suspend themselves above the floor in a full-body harness and 'fly' using the control bar in front of them, just as one would if piloting a real hang glider. Here, the affective experience comprising the kinaesthetic sensation of 'hanging' above the ground and 'flying' a 'virtually-real' aircraft was fundamental to the simulation's success.

Though devised primarily for entertainment (Halter 2006), many of the simulation techniques these machines use have been derived from professional pilot training simulators. The origins of flight simulation date from 1929 when Edwin Link's cockpit training aid was developed to facilitate pilot familiarisation and training. Comprising a replica cockpit mounted on a pneumatic motion platform, it provided three sensations of movement: pitch (nose movement up and down), roll (tipping from side to side) and yaw (nose moving left and right), and was used extensively during World War Two to train new aircrew. The first commercial aircraft simulators appeared in the late 1950s and, though they lacked any motion or visual displays, the flightdeck was identical to a real aircraft and the instruments all 'worked' which helped crew quickly familiarise themselves with the position and function of each dial, button, switch, and lever. During the late 1960s, new methods of visual display and motion simulation were devised to enable simulators to replicate all six degrees of movement; roll, pitch, yaw, heave (block movement up and down), sway (block movement left and right) and surge (acceleration and deceleration), as well as project visual images into the pilots' line of sight (Calvert 1989). Today, computer generated images (CGIs) project near photo-realistic quality 
visual displays into the simulator and provide seamless coverage of a simulated terrain or airspace (Lee 2005).

By directly addressing the body's capacities to be affected by exploiting the inadequacies of the human balance mechanism or vestibular system (Reason 1974; Thrift 2004a), modern flight simulators can accurately replicate all the kinaesthetic sensations of flight (Lee 2005). On take off, for example, positive backward pressure on the control column causes the computer controller hydraulic rams to pitch the simulator backwards although the visual cues remain stable. This movement provides a sensation of $\mathrm{g}$-force and acceleration in the pit of the stomach. At the point of rotation, the simulator remains in the same position, but the visual display begins to show the aircraft climbing away from the runway. During the simulated climb phase, the inner ear quickly adapts and, though the motion stops, the visual cues continue to move, tricking the body into thinking the aircraft is climbing. Thus, while the 'aircraft' may have pitched up by ten degrees or more, the simulator will only have moved three or four degrees from the horizontal.

The ability to impart various sensations of flight on the user is crucial as flightcrew report they don't just 'fly' an aircraft, they feel them and become attuned to detecting unusual sounds, vibrations, and sensations which may be a precursor of more serious problems. An ability to 'feel' the airframe is particularly crucial during episodes of turbulence and on landing, when a bumpy ride or a misjudged approach or excessive braking, though not necessarily damaging to the airframe, may fray the nerves of human passengers and the simulator is a vital tool in training pilots to react to such situations in a safe and predictable manner. 
Computer mediated flight simulators thus not only help pilots develop flying skills, they actively promote realistic atmospheres of affect (on atmosphere see McCormack 2008 forthcoming), as the procedures, conducts and meanings of simulations are made real by the fact that they are 'made to matter' and each 'flight' is conducted as it would be in the real world. Not only do pilots give pre-flight public address announcements from the simulator to their 'passengers', just as they would if they were commanding a real aircraft with real passengers, they warn them of upcoming turbulence and brief them on emergencies. Here, the simulation is not only being used to create a situation, it is used to condition a pilot's response to it.

Though initially only used to complement conventional line training, the physical fidelity of modern flight simulators is such that the retention of one's flying licence is dependent on satisfactory performance during simulator-based proficiency checks and pilots can qualify to fly a new type of aircraft without ever having handled a real airframe. These socalled 'Zero Flight Time Conversions' were particularly poignant for Paul Virilio, who remarked upon the 'recognition of an equivalence between simulator time and real pilot time" (Virilio 1989: 86; 1998). In many ways, however, we suggest that the simulator surpasses the experience one could gain from flying a real aircraft as a simulator can simulate situations that would be too expensive or hazardous to replicate in a real aircraft, such as bad weather coupled with hydraulic failure, an engine fire, and a fuel leak. These preparations help cultivate states and atmospheres of smoothness on a real flight, with all possible 'surprises' having already been experienced in the simulator.

The routine use of simulators for pilot training and assessment means that the behaviour of flightcrew in the real world is structured and informed by the experiences encountered (and the procedures learnt) in the virtual world of the flight simulator, and yet 
simulations do more than just allow pilots to enact pre-conditioned responses. The artificial construction of an emergency constructs a literal state of 'emergency', as the sudden illumination of red lights and the sound of warning claxons naturally induces feelings of shock, surprise and, perhaps, fear in the inexperienced. The ability to invoke such states and emotions is precisely the object of the simulation, yet one that has received scant academic attention to date.

\subsection{Foresight, Thin-Slicing and Security}

In the context of airport security, software simulations are used to augment practices that monitor and regulate flows of mobile bodies and objects at the airport. Certain objects and patterns of behaviour (for example unattended bags or apparently 'shifty' behaviour) are identified as potential threats and traced and intercepted. Object-centered surveillance is increasingly used to monitor flows of mobile objects and distinguish between threatening and innocent objects. Here, materiality loses its apparently fixed, solid and rather benign appearance by achieving a threatening indeterminacy. In response, x-ray operators and security personnel employ a form of visuality and inspection that extends beyond mere sight to foresight. In more ways than one it is a form of 'vigilant visuality', as Louise Amoore (2007) has put it, that projects-forwards in order to make judgments not over the here and now, but over the possible. Lisa Parks (2007) recently described how security screeners must cope with "uncertain materialities, mutable things, and camouflaged objects". When a "cell phone can be a gun, a lipstick can be a knife, a teddy bear can carry a weapon, a condom can be a vessel for drug-running, and a shoe can be a ticking time bomb", x-ray operators must discriminate one object from another by determining the possible from the actual. Once it has been stripped of its disguise, what an object may be, or rather, what it may become, is actively sought out. Reminiscent of Crandall's idea of an 'anticipatory form of seeing', screeners create an 'Inclination- 
position [which] scripts an object that is already ahead of itself, a shadow future state that exerts a strong gravitational pull" (Crandall 2006).

In order to train security personnel to perform these complex tasks of inclination and foresight quickly, routinely, and effectively, screeners are required to undergo continual periods of training and refreshment on simulated x-ray machines. X-ray tutor, a software simulation employed by the Canadian Aviation and Transport Security Administration (CATSA), enables prospective, as well as trained, screeners to learn how to identity different threat objects that are contained within the images that are projected onto their display screen. Using this software, screeners quickly improve their ability to identify prohibited items as well as potentially harmful combinations of otherwise 'safe' objects and supervisors can tailor learning programmes to individual students.

Such simulations are designed to improve detection rates and facilitate efficient screening of bags; X-ray tutor can purportedly decrease the time taken for a screener to identify a threat from 8 to 4 seconds, a significant reduction when hundreds of bags require processing. Drawing on research in psychological, cognitive and human computer interaction, it is thought that computer based training (CBT) such as X-ray tutor work by improving visual memory recall, supplanting on-the-spot cognition and calculation into a substratum of intuitive re-cognition (Schwaninger and Hofer 2004). Training individuals to recognize threats, as well as around 70-80 permutations of an object varied by rotation, dimensions and colour, the system enables instinctive judgments to be made that require little thought and deliberation (the so-called 'practiced eye' of the screener). In other words, such techniques encourage a 'thin-slicing' - snap judgments which determine the presence of a threat in the shortest possible time. 
Whilst the advantages of such a training system are seen in 'real-time', further developments have seen simulated threats projected onto a screener's display in real time. Of course, the basic augmentation of reality delivered by normal x-ray machines already simulates the presence of a threat by colour-coding a bag's contents according to the sorts of materials detected within it. Thus, colour palettes and hues already induce a reactionary association between colour and threat that is rendered into disposition (see Massumi 2005 on threat levels). Furthermore, Threat Image Projection Software (TIPS) works to do more than shape the pre-reflective thought required to identify a threat (Hofer and Schanwinger 2005). TIPS demands a kind of bodily and affective posturing of the screening officer so that they are continuously alert to scrutiny and modify their own behaviour accordingly.

Just as seeing is occasionally associated with a rather distanced and distracted form of engagement (Friedberg 1993; Morse 1990), distractions reducing screener attention to a threat are being transformed according to shifting forms of security-software design (on attention see Adey 2007). However, TIPS is intended to make sure that the X-ray screener is in a continuously attentive state and works by projecting a simulated threat onto the displayed $\mathrm{x}$-ray image of a real passenger's luggage. Screeners are expected to spot the threat image and indicate that the bag should be manually searched. TIPS will then signal whether the image was a virtual (i.e. whether it was simulated by the software) or an actual threat. Should an operator miss a simulated threat, TIPS will automatically alert a supervisor. This continual aggravation of screener attentiveness is heightened by the knowledge that an individual's performance over the course of a shift is recorded the expectation clearly being that they will want to continually better their 'score' and outperform their colleagues. Resembling a kind of Foucauldian discipline, screeners must assume that they are constantly being monitored and thus they must remain more than 
attentive. TIPS demands a state of 'alertness', where one is ready for an unknown but omnipresent and imminent threat.

\subsection{Real-time simulations}

In our final example in this section, we examine forms of software simulation that are working, like the TIPS software discussed above, to close the gap between anticipation and action by functioning in near real-time. The Traffic Control and Collision Avoidance System (TCAS), which is installed in all commercial aircraft with over 19 seats, enables pilots to 'see' the position of other air traffic in the surrounding airspace and warns them of possible mid-air collisions. The system automatically scans, once per second, a minimum of 15 nautical miles ahead and 7.5 nautical miles behind the aircraft. Working on the same principle as secondary surveillance radar, small radio transmitters, called transponders, are used to positively identify aircraft on the navigation display screen. In addition to identifying all transponder-equipped aircraft within its scanning range, TCAS interrogates the transponders of these other aircraft to evaluate whether their proximity (in terms of track, altitude, vertical speed, or heading) poses a collision risk. Within a fraction of a second, the system assesses all the known parameters of the target aircraft and simulates possible future outcomes based on the threat level neighbouring aircraft pose. Should a collision be imminent, the system provides visual and aural warnings to pilots and instructs them to take avoiding action, if required, to prevent a collision.

The nature of any such airborne 'threat' is represented by a series of coloured shapes and data labels that change according to position and extent of the threat. If the space between two aircraft begins to close, the threat level is progressively upgraded and a spoken deconflicting 'resolution advisory' is broadcast 40 seconds before impact. This orders an evasive manoeuvre such as "climb" or "descend" and details the rate at which the 
action must be performed. In such a situation, the system in one aircraft instructs their pilots to climb, while the other system orders a descent. Yet despite invoking and augmenting anticipatory forms of seeing, the system is not infallible. In 2000 , over 70 people died in a mid-air collision above Überlingen, Germany, as a result of a pilot overriding TCAS advice (BFU 2004; Bennett 2004).

Other flightdeck systems, through similar automated real-time measurement and simulation, continually monitor the integrity of individual aircraft systems. These, we suggest, are bearing witness to new kinds of simulation that do not just advise and provoke reaction from human operators, but actually do the reacting themselves. In addition to conveying all the 'basic' information about a flight, from altitude, to airspeed and heading, flightdeck displays relay information from the centralised aircraft monitoring system which alert pilots, through a combination of visual, aural, and tactile warnings, to imminent future dangers, including windshear and aerodynamic stalls, in addition to any system faults. This advanced warning should give pilots sufficient time to shut down any malfunctioning systems and take all necessary precautions to prevent an emergency. The flight management system also suppresses certain information according to flight stage and actively determines what information the pilots can access (and therefore 'know') at any given time to reduce pilot workload and the potential for cognitive 'overload'.

Modern 'fly-by-wire' systems also rely on continuous simulation of immediate-future events. Unlike the older generation of aircraft, modern Airbus aircraft are flown using a small sidestick controller (similar in appearance to a gaming joystick on a home computer), which is connected electronically to a series of networked computer processors. These continually evaluate the pilot's control inputs and project their impact 
on the airframe in the immediate future. Should a pilot make a severe or dangerous manoeuvre, the onboard computers will immediately take corrective action to prevent it endangering the airframe or its occupants by ensuring the aircraft remains within permitted thresholds. While recognising the huge technological achievement underpinning such systems, some analysts have expressed concern that the cognitive skills of human pilots are being eroded (Singh et al 1997).

As Hourizi and Johnson $(2003,860)$ note, '[t] he acquisition, maintenance and repair of awareness [on the flightdeck] is...particularly difficult to achieve and can be devastating when lost'. Beaty (1991), and others, chronicle a catalogue of aircraft disasters that have been attributed, at least in part, to crew confusion or pilot error. In light of these dangers, pilots are trained to take a very active role in the management of an automated flightdeck. Indeed, as flightdeck software has got increasingly complicated, it is vital pilots develop 'appropriate individual and shared understandings of what the technology is doing, what it knows [and] what is motivating it to act in certain ways...at certain times' (Nevile 2004: 207).

\section{Discussion:}

So far, this paper has charted the development and use of software simulations in a number of different modes and contexts of aerial transportation. In our discussion, we debate the implications of such study for the conceptualization and empirical examination of geographies of anticipation.

Using examples from military and commercial aviation, we have argued that software simulations as tools of anticipation represent a distinctive and particular way of tackling the socially constructed uncertainties of aeromobility. From passenger behaviour in the 
check-in hall to the training of fighter pilots, we have suggested that virtually all aspects of modern air travel are anticipated and mediated by software simulation to a greater or lesser degree. This is not to suggest that the notion of managing or governing by anticipation is anything new, or indeed unique to aviation, but we do believe that the multiplicity of ways in which the aerospace industry has addressed the inherent uncertainties associated with different expressions of mobility - through the construction of particular virtual spaces of representation and anticipation - is significant and we note evidence of a common alignment between mobility, indeterminacy and uncertainty. Such a tendency is exemplified by Foucault's (1977; see especially 2007) treatment of the $19^{\text {th }}$ century town where he outlines the continual attempts to govern uncertain circulations of vagrants, plague and disease, or indeed the complex trade, exchange and mobility of grain movement. For Foucault, this invariably meant the association of circulation, or mobility, with uncertainty and unpredictability - the aleatory. In order to control it, mobility was met by various forms of disciplinary and biopolitical anticipatory measures; from makingknown through statistics; to the calculation of probabilities within 'the plan'; to the material structuring of behaviour by the design of circulatory spaces such as streets and roads (see also Dillon 2007).

Yet, models and software simulations do not necessarily seek to control mobilities and aeromobilities. Within Geography, simulations were utilised within a wider context of a variety of physical models (Chorley and Haggett, 1967) as metaphors and representations (Lowe and Moryadas 1976) that better described mobility and transport systems. River systems were modelled as network diagrams resembling the wiring of circuit boards (Haggett 1972). The movements of individual customers to markets were modelled as particles subject to gravitational attraction. Some models were deployed as a means to get a handle on different human and physical phenomena, while others sought to make 
apparently indeterminate circulations ostensibly predictable and determinable. Whilst we have witnessed similar approaches towards software simulations in the context of airtravel, to continue our analysis in this way falls short in addressing their more-than representational affective and emotional register. Being aware of the performative experiences of software simulations illustrates their powerful orientation to the possible and the uncertain by making the virtual present and real as a bodily experience.

In focusing on the affective embodiments of software simulations, we suggested that it was through the management and training of specific affects and affective states that software simulations are increasingly aimed. How uncertain circulations and futures could be trained and prepared for was a key issue in simulation design. Brian Massumi's (2005a; 2005b) tracking of various forms and technologies of pre-emption, from the colour coded threat index deployed by the Department of Homeland Security, to the event of an airport security threat, are instructive in this light. Anderson sums up, "Affect is a necessary component of anticipatory governance because it resolves the paradox of how the event can remain virtual, that is 'be' a threat or an opportunity, but at the same time is real in effect. i.e. it causes some form of event in the present" (Anderson, 2007: 159). In other words, as forms of anticipation such as pre-emption attempt to govern uncertainty they inevitably impel that threat or possibility to come into being.

In our examples, we have seen how these 'disruptions' are both aimed-for and engineered (Thrift 2004a). Software simulations make the future present and actionableupon by alerting the users to future possibilities. Flight simulators, for instance, deliberately create potential emergencies in order to create surprise, confusion, fear and shock so the feeling of a feeling may become known. This kind of preparedness tests the mental resilience and ability of pilots to cope with such a future. They work not only to 
prevent an incident from occurring, but also to mitigate its effects if it does. Thus, as Anderson (forthcoming) argues, it is through "both embodying affects and emotions in the skills and techniques that enable imaginative [and, we might add, software mediated] anticipation". The value of flight simulators is not only to imagine and experience potential emergencies and scenarios so that they can be 'fixed', but to create particular affective states so that they might be dealt with rationally and efficiently or rapidly and instinctively. As we have argued, the gap between such training and when such skills might be needed is diminishing - the projection of a simulated threat onto a security screener's display unit, for example, is intended to enhance the screener's detection capabilities just as much as it is intended to induce a constant state of 'vigilance' and attention.

\section{Conclusion:}

This paper has sought to expose the complex interplay of real and virtual space. We have shown how software and simulation do not privilege real over virtual spaces or viceversa, but have suggested that aviation cannot function without either and constantly operates in both. In extending Dodge and Kitchin's thesis, we have demonstrated the relationship between code, simulation and space is increasingly formative of an embodied, affective and real virtuality that is quite different to Castells' (1996) initial meaning of the term. Software simulations are used to anticipate and prepare for future events with predisposed actions that are learnt by exposing their users to the sorts of feelings and states they are likely to encounter. The virtual, in other words, is made real by cultivating certain kinds of feelings, intensities and atmospheres.

In his recent analysis of nanotechnology as a practice of affective and anticipatory governance, Ben Anderson asks how 
“anticipatory epistemic objects (such as 'trends' or 'scenarios') and/or virtualities (such as 'threats' or 'opportunities') emerge, circulate and achieve effects?" (Anderson 2007: 163-164)

In addressing Anderson's question we have suggested how software simulations engage specific body/brain/culture networks in air transportation. From virtual airports to cyber warfare, we have suggested anticipatory software simulations are radically altering human spatialities and fundamentally changing the way people interact with aircraft, their environment and, increasingly, each other. As these trends are set to continue, we have explored an increasing blurring of the distinctions between simulation, the simulated (virtual), and the real (present), as they develop. Software simulations are increasingly able to pre-mediate in real-time as we have seen. In other contexts, citing the example of how the unmanned aerial reconnaissance vehicle, the 'predator', is controlled using a Playstation style controller, Steve Graham (2008 in press) notes how for, "the US military personnel doing the piloting, this 'virtual' work is almost indistinguishable from a 'shootem-up' video game (except that the people who die are real)". And in civilian contexts, we note the increasing popularity of online digital 'airworlds', such as VATSIM (Virtual Air Traffic Simulation Network) and GlobalVAC (Virtual Aviation Community) as well as the forthcoming programme 'Air Traffic Chaos' for the Nintendo DS gaming platform, which suggest that software is often not merely simulating an experience but, increasingly, is the experience.

\section{References}

Adey, P. (2007) 'May I have your attention': Airport geographies of spectatorship, position and (im)mobility, Environment and Planning D-Society \& Space 3: 515-536 
Adey, P. (2008 in press) Aeromobilities: geographies, spaces, visualities, Geography Compass

Adey, P. (2009 in press) Facing Airport Security: affect, biopolitics and the preemptive securitisation of the mobile body, Environment and Planning D: Society and Space

Adey, P., Budd L. and Hubbard P. (2007) Flying Lessons: exploring the social and cultural geographies of global air travel, Progress in Human Geography 31: 773-791

Amoore, L. (2007) Vigilant Visualities: The Watchful Politics of the War on Terror, Security Dialogue 38: 215-232

Anderson, B. (2002) A Principle of Hope: Recorded Music, Listening Practices and the Immanence of Utopia, Geografiska Annaler B. 84: 211-227.

Anderson, B. (2006) Becoming and being hopeful: towards a theory of affect, Environment and Planning D 24: 733-752

Anderson, B. (2007) Hope for nanotechnology: anticipatory knowledge and the governance of affect, Area 39: 156-165

Anderson, B. (forthcoming) Threat and Affectivity: preparedness and the war on terror, Mimeo

Barnes, T.J. (2001) Retheorizing Economic Geography: From the Quantitative Revolution to the "Cultural Turn", Annals-Association of American Geographers 91: 546-565 
Barnes, T. J. (2008 forthcoming) Geography's underworld: The military-industrial complex, mathematical modelling and the quantitative revolution, Geoforum

Barnes, T. J. and Farish, M. (2006) Between Regions: Science, Militarism, and American Geography from World War to Cold War, Annals of the Association of American Geographers 96(4): 807-826

Beaty, D. (1991) The naked pilot: the buman factor in aircraft accidents. London: Methuen.

Bennett, S. (2004) The $1^{\text {st }}$ July 2002 mid-air collision over Űberlingen, Germany: A Holistic Analysis, Risk Management: An International Journal 6: 31-49.

BFU (Bundesstelle für Flugunfalluntersuchung) (2004) Accidents Investigation. Investigation Report AX001-1-2/02. German Federal Bureau of Aircraft Accidents Investigation Retrieved from www.bfu-web.de on 28/06/2005

Bissell, David (2007) Animating Suspension: waiting for mobilities, Mobilities 2 (2): $277-298$.

Blake, W.T. (1923) Some Difficulties in Flying Round the World, Geographical Journal 61: 273-279

Bowen, J. (2002) Network Change, Deregulation, and Access in the Global Airline Industry, Economic Geography 78: 425-440 
Buchanan, I. (1997) The Problem of the Body in Deleuze and Guattari, Or, What Can a Body Do?, Body and Society 3: 73-91

Buscher, M. (2006) Vision in Motion, Environment and Planning A 38 (2): 281-299.

Budd, L. (2008, in press) Air craft: producing UK airspace. In Cwerner, S., Kesslring, S. and Urry, J. (Eds.) Aeromobilities. London: Routledge.

Burghouwt, G. and Huys M. (2003) Deregulation and the Consequences for Airport Planning in Europe, Disp37-45

Butler, D.L. (2001) Technogeopolitics and the struggle for control of world air routes, 1910-1928, Political Geography 20: 635-658

Byrd, R.E. (1925) Flying over the Arctic, National Geographic November: 519-532

Calvert, B. (1989) Flying Concorde. Shrewsbury: Airlife.

Carter, S. and McCormack, D. (2007) Film, geopolitics, and the affective logics of intervention, Political Geography 25: 228-245

Castells, M. (1997) The Rise of the Network Society. Oxford: Blackwell.

Chorley, R.J. and Haggett P. (Eds.) (1967) Models in geography. London: Methuen. 
Clough, P. T. (2000) Autoaffection: unconscious thought in an age of teletechnology. Minneapolis: University of Minnesota Press.

Collier, S., Lakoff A. and Rabinow P. (2004) Biosecurity: Proposal for an Anthropology of the Contemporary, Anthropology Today 20:

Crandall, J. (2006) Precision + Guided + Seeing, CTheory

www.ctheory.net/articles.aspx?id=502

Cresswell, T. (2006) On the move: the politics of mobility in the modern west. London: Routledge.

Curry, M.R. (1998) Digital places: living with geographic information technologies. London: Routledge.

Cwerner, S., Kesselring, S., and Urry, J. (Eds.) (2008, in press) Aeromobilities London: Taylor and Francis.

De Landa, M. (1997) A thousand years of nonlinear history. New York: Zone Books.

Demeritt, D. (2001) The Construction of Global Warming and the Politics of Science, Annals- Association of American Geographers 91: 307-337

Derudder, B., Devriendt L. and Witlox F. (2007) Flying Where You Don't Want to Go: An Empirical Analysis of Hubs in the Global Airline Network, Tijdschrift Voor Economische En Sociale Geografie 98: 307-324 
Derudder, B. and Witlox F. (2005) An Appraisal of the Use of Airline Data in Assessing the World City Network: A Research Note on Data, Urban Studies 42: 2371-2388

Dillon, M. (2007) Governing Terror: The State of Emergency of Biopolitical Governance, International Political Sociology 1: 7-28

Dewsbury, J-D., Harrison, P., Rose, M., and Wylie, J. (2002) Enacting Geographies Geoforum 33 (4): 437-440.

Dodge, M. and Kitchin R. (2004) Flying through code/space: the real virtuality of air travel, Environment and planning A 36: 195-211

Dodge, M. and Kitchin R. (2005) Code and the Transduction of Space, Annals-Association of American Geographers 95: 162-180

Dowling, D. (1999) Experimenting on Theories, Science in Context 12: 261-274

Edwards, P.N. (1996) The closed world: computers and the politics of discourse in Cold War America. Cambridge, Mass. ; London: MIT Press.

Foucault, M. (1977) Discipline and punish: the birth of the prison. London: Allen Lane.

Foucault, M. (2007) Spaces of security: The example of the town. Lecture of 11th January 1978, Political Geography 26: 48-56

Friedberg, A. (1993) Window shopping: cinema and the postmodern. Berkeley: University of California Press. 
Fuller, G. and Harley R. (2004) Aviopolis: a book about airports. London: Blackdog.

Ghamari-Tabrizi, S. (2005) The worlds of Herman Kabn : the intuitive science of thermonuclear war. Cambridge, Mass. ; London: Harvard University Press.

Gladwell, M. (2005) Blink: the power of thinking without thinking. London: Allen Lane.

Gordon, A. (2004) Naked airport: a cultural history of the world's most revolutionary structure. New York: Metropolitan Books H. Holt.

Gottdiener, M. (2000) Life in the air: surviving the new culture of air travel. Lanham, Md.: Rowman \& Littlefield.

Graham, S. (1998) Spaces of surveillant simulation: new technologies, digital representations, and material geographies, Environment and Planning D-Society \& Space 16: 483-504

Graham, S. (2004) Vertical Geopolitics: Baghdad and After, Antipode 36: 12-23

Graham, S. (2008 in press) War play: Practising urban annihilation F. von Borries, S. Walz and M. Botther (Eds.) Space Time Play: On the Synergy Between Computer Games, Architecture, and Urbanism. Birkhauser, Basel

Gray, C.H. (1997) Postmodern war: the new politics of conflict. London: Routledge. 
Grusin, R. (2004) Premediation, Criticism 46: 17-40

Guhathakurta, S. (2002) Urban modeling as storytelling: using simulation models as a narrative, Environment and Planning B-Planning \& Design 29: 895-911

Hables Gray, C. (1997) Post-modern War, London: Routledge.

Haggett, P. (1972) Geography: a modern synthesis, New York: Harper and Row.

Halter, E. (2006) From Sun Tæu to Xbox: War and Video Games, London: Perseus Publishing.

Hannam, K., Sheller M. and Urry J. (2006) Editorial: Mobilities, Immobilities and Moorings, Mobilities 1: 1-22

Harvey, D. (1969) Explanation in geography London: Edward Arnold.

Hickman, M. (2007) The world's worst airports, The Independent Extra 28/11/2007: 2

Hofer, F., Schwaninger, A. (2005) Using threat image projection data for assessing individual screener performance, WIT Transactions on the Built Environment 82: 417-426

Hourizi, R., Johnson, P. (2003) Towards an explanatory, predictive account of awareness, Computers and Graphics 27: 859-872 
Hudlicka, E. (2003) To feel or not to feel: The role of affect in human-computer interaction, International Journal of Human-Computer Studies 59(1-2): 1-32

Iyer, P. (2000) The global soul: jet lag, shopping malls and the search for home. London: Bloomsbury.

Kaplan, C. (2006) Mobility and war: the cosmic view of US 'air power', Environment and Planning A 38: 395-407

Kerr, R. (1994) Climate Modeling’s Fudge Factor Comes Under Fire, Science 265: 1528

Lakoff, A. (2007) Preparing for the Next Emergency, Public Culture 19: 247-271

Lee, A. T. (2005) Flight Simulation Virtual Environments in Aviation, Aldershot: Ashgate

Lessig, L. (1999) Code: and other laws of cyberspace. New York, N.Y.: Basic Books.

Light, R.U. (1935) Cruising by airplane: Narrative of a journey around the world, Geograpical Review 25: 565-600

Lorimer, H. (2005) Cultural geography: the busyness of being `more-thanrepresentational', Progress in Human Geography 29: 83-94

Lorimer, H. (2008) Cultural geography: non-representational conditions and concerns, Progress in Human Geography 32 (4): 551-559 
Lowe, J.C. and Moryadas S. (1976) The geography of movement. Boston [Mass.] ; London: Houghton Mifflin.

Lyon, D. (2003) Airports as Data Filters: Converging Surveillance Systems after September 11th, Journal of Information Communication and Ethics in Society 1: 13-20

MacKenzie, D.A. (2006) An engine, not a camera: how financial models shape markets. Cambridge, Mass.; London: MIT.

Massey, D. (1989) Introduction R. Peet and N. J. Thrift (Eds.) New models in geography: the political-economy perspective (Unwin Hyman, London) pp. 2 v.

Massumi, B. (2002) Parables for the Virtual: movement, affect, sensation. Durham, N.C.: Duke University Press.

Massumi, B. (2005a) Fear (The Spectrum Said), Positions 31:

Massumi, B. (2005b) The future birth of an affective fact. In. The sinues of the present genealogies of biopolitics, May: Montreal

McCormack, D.P. (2003) An event of geographical ethics in spaces of affect. Transactions of the Institute of British Geographers, 28: 488-507.

McCormack, D. P. (2008, forthcoming) Engineering affective atmospheres and aerostatic bodies: on the moving geographies of the 1897 Andrée expedition. Cultural Geographies 
McKenzie J (1994) Virtual Reality: Performance, Immersion, and the Thaw The Drama Review, 38(4): 83-106

McKenzie J (2001) Perform or Else: From Discipline to Performance London: Routledge

McNeese, M. D. (2003). New visions of human-computer interaction: Making affect compute. International Journal of Human-Computer Studies, 59 (1): 33-53.

Mirowski, P. (2001) Macbine dreams: economics becomes a cyborg science. Cambridge: Cambridge University Press.

Morse, M. (1990) An Ontology of Everyday Distraction: The Freeway, the Mall, and Television P. Mellencamp (Eds.) Logics of Television: Essays in Cultural Criticism (Indiana University Press, Bloomington) pp. 193-221

Nevile, M. (2004) Integrity in the Airline Cockpit: Embodying Claims About Progress for the Conduct of an Approach Briefing, Research on Language and Social Interaction 37: $447-480$

Norris, G., Wagner, M. (1996) Boeing 777, Osceola, Wisconsin: Motorbooks International

O'Sullivan, D. and Haklay M. (2000) Agent-based models and individualism: is the world agent-based?, Environment and Planning A 32: 1409-1425

Parks, L. (2007) Points of departure: The culture of US airport screening, Journal of Visual Culture 6: 183-200 
Pearman, H. (2004) Airports: A Century of Architecture. London: Laurence King.

Picard, L. (2000) Affective Computing. Cambridge, Mass: MIT Press.

Pickles, J. (1995) Ground Truth: The Social Implications of Geographic Information Systems. Kentucky: University of Kentucky Press.

Ploszajska, T. (1996) Constructing the subject: geographical models in English schools, 1870-1944, Journal of Historical Geography 22: 388-398

Rau, E.P. (2005) Combat science: the emergence of Operational Research in World War II, Endeavour 29: 156-161

Reason, J. (1974) Man in Motion, London: Weidenfeld and Nicolson.

Rheinberger, H.-J.r. (1997) Toward a history of epistemic things : synthesizing proteins in the test tube. Stanford, Calif.: Stanford University Press.

Salter, M.B. (2004) Passports, Mobility, and Security: How smart can the border be?, International Studies Perspectives 5: 71-91

Salter, M.B. (2007) Governmentalities of an airport: Heterotopia and Confession, International Political Sociology 1: 49-66

Schroeder R (1996) Possible Worlds: The Social Dynamics of Virtual Reality Technology Boulder, Colorado: Westview Press 
Schuurman, N. (2004) GIS: a short introduction. Malden, MA. ; Oxford: Blackwell Pub.

Schwaninger, A. and Hofer, F. (2004) Evaluation of CBT for increasing threat detection performance in X-ray screening. In: K. Morgan and M. J. Spector (Eds.), The Internet Society: Advances in Learning, Commerce and Security, Wessex: WIT Press, 147-156

Shackley, S. and Darier E. (1998) Seduction of the Sirens: global climate change and modelling, Science and Public Policy 25: 313-326

Shackley, S. and Wynne B. (1996) Representing Uncertainty in Global Climate Change Science and Policy: Boundary-Ordering Devices and Authority, Science Technology and Human Values 21: 275-302

Shackley, S., Young P., Parkinson S. and Wynne B. (1998) Uncertainty, Complexity and Concepts of Good Science in Climate Change Modelling: Are GCMs the Best Tools?, Climatic Change 38: 159-205

Sheller, M. (2004) Automotive Emotions: feeling the car, Theory, Culture and Society 21 (45): $221-242$

Singh, I. L, Molloy, R. and Parasuraman, L. (1997) Automation-induced monitoring inefficiency: role of display location, International Journal of Human-Computer Studies 46: $17-30$ 
Sismondo, S. (1999) Models, Simulations, and Their Objects, Science in Context 12: 247260

Sismondo, S., Gissis S. and Peterson A.C. (2000) Modeling and simulation, Social studies of science 30: 793-799

Smith, D. and Timberlake M. (1995) Conceptualising and Mapping the Structure of the World System's City System F. Moulaert and A. Shacher (Eds.) Cities, Enterprises and Society at the Eve of the 21st Century (Carfax Publishing Company, 32; Number 2 pp. 287

Smith, D. and Timberlake M. (1998) Cities and the Spatial Articulation of the World Economy through Air Travel P. S. Ciccantell and S. G. Bunker (Eds.) Space and Transport in the World-System (Distropa Ltd, Issue 191 pp. 213-240

Solnit, R. (2003) River of shadows : Eadweard Muybridge and the technological wild west. New York: Viking.

Sykes, F.H. (1920) Imperial Air Routes, The Geographical Journal LV: 241-262

Taaffe, E.J. (1956) Trends in airline passenger traffic: A geographic case study, Geographical Review XLVI: 219-238

Taaffe, E.J. (1959) Trends in airline passenger traffic: A geographic case study, Annals of the Association of American Geographers 49: 393-408 
Taaffe, E.J. (1962) The urban hierarchy: An air passenger definition, Economic Geography 38: $1-14$

Taylor, G. (1919) Air routes to Australia, Geographical Review 7: 256-261

Thrift, N. (2004a) Intensities of feeling: Towards a spatial politics of affect, Geografiska Annaler Series B 86: 57-78

Thrift, N. (2004b) Remembering the technological unconscious by foregrounding knowledges of position, Environment and Planning D 22: 175-190

Thrift, N. (2006) Re-inventing invention: new tendencies in capitalist commodification, Economy and Society 35: 279-306

Thrift, N. and French S. (2002) The automatic production of space, Transactions- Institute of British Geographers 27: 309-335

Turkle, S. (1995) Life on the screen : identity in the age of the Internet. London: Weidenfeld \& Nicolson, 1996.

Ueno, N. and Kawatoko Y. (2003) Technologies making space visible, Environment and Planning A 35: 1529-1546

Urry, J. and Sheller M. (2006) The new mobilities paradigm, Environment and Planning A 38: $207-226$ 
Urry J (2007) mobilities London, Routledge

Virilio, P. (1989) War and cinema : the logistics of perception. London: Verso.

Virilio, P. (1998) Military space in Der Derain, J. (Ed.) The Virilio Reader, Oxford:

Blackwell: 22-28

Vowles, T.M. (2006) Geographic Perspectives of Air Transportation, Professional Geographer 58: 12-19

Walford, R. (1981) Geography Games and Simulations: learning through experience, Journal of Geography in Higher Education 5:

Walford, R. (1995) A Quarter-Century of Games Simulations in Geography, Simulation and Gaming 26: 236

Weizmann, E. (2002) The Politics of Verticality, Open Democracy 24/04/2002:

Wilkes, B. (2001) Silver Flag: A Concept for Operational Warfare, Aerospace Power Journal Winter.

Wilkins, B. (1928) The Flight from Alaska to Spitzbergen, 1928, and the Preliminary Flights of 1926 and 1927, Geographical Journal 18: 527-555

Williams, A. (2007) Hakumat al tayarrat: The role of air power in the enforcement of Iraq's boundaries, Geopolitics 12: 505-528 
Zook, M.A. and Brunn S.D. (2006) From Podes to Antipodes: Positionalities and Global Airline Geographies, Annals-Association of American Geographers 96: 471-490 